\title{
Folate Deficiency Was Associated with Increased Alanine Aminotransferase and Glutamyl Transpeptidase Concentrations in a Chinese Hypertensive Population: A Cross-Sectional Study
}

\author{
Wen-Xing $\mathrm{LI}^{1,2}$, Wei $\mathrm{LI}^{3}$, Jia-Qian CAO ${ }^{4,5}$, Haiyue YAN ${ }^{3}$, Yuanyuan $\mathrm{SuN}^{3}$, \\ Hong ZHANG ${ }^{3}$, Qiang ZHANG ${ }^{3}$, Ling TANG ${ }^{3}$, Manman WANG ${ }^{3}$, \\ Jing-Fei HuANG ${ }^{2,6,7}$ and Dahai $\mathrm{LIU}^{3, *}$ \\ ${ }^{1}$ Institute of Health Sciences, Anhui University, Hefei 230601, Anhui, P. R. China \\ ${ }^{2}$ State Key Laboratory of Genetic Resources and Evolution, Kunming Institute of Zoology, \\ Chinese Academy of Sciences, Kunming 650223, Yunnan, P. R. China \\ ${ }^{3}$ Center for Stem Cell and Translational Medicine, School of Life Sciences, Anhui University, \\ Hefei 230601, Anhui, P. R. China \\ ${ }^{4}$ CAS Key Laboratory of Pathogenic Microbiology \& Immunology, Institute of Microbiology, \\ Chinese Academy of Sciences, Beijing 100101, P. R. China \\ ${ }^{5}$ University of Chinese Academy of Sciences, Beijing 100049, P. R. China \\ ${ }^{6}$ KIZ-SU Joint Laboratory of Animal Models and Drug Development, College of Pharmaceutical Sciences, \\ Soochow University, Suzhou 215123, Jiangsu, P. R. China \\ ${ }^{7}$ Collaborative Innovation Center for Natural Products and Biological Drugs of Yunnan, \\ Kunming 650223, Yunnan, P. R. China \\ (Received February 29, 2016)
}

\begin{abstract}
Summary Alanine aminotransferase (ALT), aspartate transaminase (AST), and glutamyl transpeptidase (GGT) were three key enzymes in the hepatic metabolism. This study aimed to investigate the effect of homocysteine (Hcy) metabolism gene polymorphisms and serum Hcy and folate level on the hepatic functions in a Chinese hypertensive population. A representative sample with 480 subjects aged 28-75 was enrolled in 2005.9-2005.12 from six hospitals in different Chinese regions. Serum ALT, AST and GGT were measured by using an automatic biochemistry analyzer. Serum Hcy was measured by high-performance liquid chromatography, and serum folate was measured by chemiluminescent immunoassay. Known genotypes were detected by PCR-RFLP methods. The results showed that the MTHFR C677T mutation was related a decreased serum AST level $(r=-0.11, p=0.026)$, whereas the MTHFR A1298C mutation elevated serum AST level $(r=0.11, p=0.032)$. Furthermore, multiple regression analysis showed that folate deficiency was associated with higher serum $\operatorname{ALT}(\beta$ (SE): $0.13(0.06), p=0.031)$ and GGT level $(\beta$ (SE): $0.18(0.07), p=0.011)$. However, serum Hcy level may not affect the hepatic functions. Our data suggested that hepatic functions were affected by MTHFR gene polymorphisms and serum folate level. Further studies are needed to confirm these correlations in a larger population.
\end{abstract}

Key Words folate deficiency, MTHFR gene polymorphisms, alanine aminotransferase, aspartate transaminase, glutamyl transpeptidase

Fatty liver disease (FLD), including primary non-alcoholic fatty liver disease (NAFLD) and the severe form, non-alcoholic steatohepatitis (NASH) is the most common form of liver disease and is increasing throughout the world (1). In Western adults, the prevalence of NAFLD assessed by ultrasound is $20-30 \%$ and the prevalence of NASH is $3-16 \%(2)$. Alanine aminotransferase (ALT), aspartate transaminase (AST) and glutamyl transpeptidase (GGT) are three key enzymes in the liver metabolism. Studies showed that high levels of ALT, AST and GGT were associated with liver disease (3). Furthermore, serum ALT and AST levels showed relevance with the histopathological changes in liver biopsies of hepatitis C patients (4). In one carbon metabolism, folate is

\footnotetext{
*To whom correspondence should be addressed.
}

E-mail: seansean2014@126.com closely related to many important biochemical processes in vivo. A mouse experiment suggested that maternal low folate and selenium diet altered liver gene expression patterns in the offspring after weaning (5). And a previous study showed that folate supplementation reduced the serum ALT level in high baseline ALT (>40 IU/L) individuals (6). In addition, a higher serum homocysteine (Hcy) level also showed strongly correlation with liver disease $(7,8)$.

Methylenetetrahydrofolate reductase (MTHFR), methionine synthase (MTR) and methionine synthase reductase (MTRR) are three key regulatory enzymes in the folate and Hcy metabolisms (9). MTHFR catalyses the reduction of 5,10-methylenetetrahydrofolate $(5,10$ MTHF) to 5-methyltetrahydrofolate (5-MTHF) and 5-MTHF is a cofactor for Hcy methylation to methionine when catalyzed by the MTR-cobalamin complex (10, 
11). Over time, the cobalamin(I) cofactor of MTR is oxidized to form cobalamin(II), leading to inactivation of MTR. Thus, MTRR is required for reversion of oxidized cobalamin(II) to $\mathrm{CH}_{3}$-cobalamin(III) to maintain the activity of MTR (12).

MTHFR C677T and A1298C are two common mutations in the MTHFR enzyme. A study carried out in Turkey showed both $677 \mathrm{C} / \mathrm{T}$ and $1298 \mathrm{~A} / \mathrm{C}$ mutations were more common in NAFLD groups compared with the controls (13). However, another study in a Brazilian population showed that the MTHFR C677T and A1298C polymorphisms are not genetic risk factors for the development of NAFLD whereas higher Hcy level was related the incidence of NAFLD (14). The effect if polymorphisms of MTR A2756G and MTRR A66G on the hepatic functions have not been adequately studied.

Our previous studies found that the mutations of MTHFR C677T, MTHFR A1298C, MTR A2756G and MTRR A66G jointly elevate the folate deficiency risk (15). Further, the combination effects of genotypes and low folate increased the dyslipidemia risk (16). Based on the metabolism connections between folate and these hepatic enzymes, we hypothesized that these four gene polymorphisms in combination with Hcy/folate may affect the hepatic functions. The aim of the present study was to investigate the effects of serum folate and Hcy and genotypes on the hepatic functions in Chinese hypertensive patients.

\section{MATERIALS AND METHODS}

This study was conducted using data collected in a previous study (16). This was a multicenter, randomized, double-blind controlled trial in hypertensive Chinese adults. Details regarding "Study subjects," "Randomization and double blinding," "Data collection procedures," and "Laboratory tests" have been previously described $(16,17)$. In total, 480 patients with mild or moderate hypertension were recruited from six hospitals in different Chinese regions (Ha'rbin, Shanghai, Shenyang, Beijing, Xi'an, and Nanjing) from September to December 2005. All six hospitals were certified as clinical pharmacology centers by the State Food and Drug Administration in China. This study was approved by the Ethics Committee of Peking University First Hospital, Beijing, China. All procedures followed were in accordance with the ethical standards of the responsible committee on human experimentation (institutional and national) and with the Helsinki Declaration of 1975, as revised in 2000(5) (18). The purpose and procedures of the study were carefully explained to all participants, and written informed consent was obtained from each participant.

Demographic and clinical information was obtained at baseline. Blood samples collected at baseline were used for the measurement of serum Hcy, folate, ALT, AST and GGT levels. All these tests were performed in the six study center laboratories; serum ALT, AST and GGT were measured by using an automatic biochemistry analyzer (17). Hcy concentration was determined in duplicate by high-performance liquid chromatography. The intra- and inter-assay coefficients of variation
Table 1. Clinical and epidemiologic characteristics of the study population.

\begin{tabular}{|c|c|c|}
\hline Characteristic & $n$ & Value/Percentage \\
\hline Age, y & 480 & $56.8 \pm 10.0$ \\
\hline Height, cm & 480 & $162.7 \pm 8.1$ \\
\hline Weight, kg & 480 & $68.4 \pm 11.0$ \\
\hline BMI, $\mathrm{kg} / \mathrm{m}^{2}$ & 480 & $25.8 \pm 3.4$ \\
\hline SBP, mmHg & 480 & $154.3 \pm 11.7$ \\
\hline DBP, mmHg & 480 & $93.3 \pm 8.5$ \\
\hline Folate, $\mathrm{nmol} / \mathrm{L}$ & 479 & $12.6 \quad(9.7-15.7)$ \\
\hline $\mathrm{Hcy}, \mu \mathrm{mol} / \mathrm{L}$ & 480 & $13.2(9.9-15.9)$ \\
\hline ALT, IU/L & 435 & $22.7(16.0-32.6)$ \\
\hline AST, IU/L & 377 & $24.4(20.0-31.0)$ \\
\hline GGT, IU/L & 412 & $21.2(14.0-30.0)$ \\
\hline \multicolumn{3}{|l|}{ Sex } \\
\hline Male & 208 & $43.3 \%$ \\
\hline Female & 272 & $56.7 \%$ \\
\hline \multicolumn{3}{|l|}{ Clinical Centers } \\
\hline Ha'rbin & 60 & $12.5 \%$ \\
\hline Shanghai & 64 & $13.3 \%$ \\
\hline Shenyang & 79 & $16.5 \%$ \\
\hline Beijing & 120 & $25.0 \%$ \\
\hline Xi'an & 78 & $16.3 \%$ \\
\hline Nanjing & 79 & $16.5 \%$ \\
\hline \multicolumn{3}{|l|}{ MTHFR C677T } \\
\hline $\mathrm{CC}$ & 118 & $24.6 \%$ \\
\hline $\mathrm{CT}$ & 242 & $50.4 \%$ \\
\hline $\mathrm{TT}$ & 120 & $25.0 \%$ \\
\hline \multicolumn{3}{|c|}{ MTHFR A $1298 \mathrm{C}$} \\
\hline $\mathrm{AA}$ & 332 & $69.9 \%$ \\
\hline $\mathrm{AC}$ & 127 & $26.7 \%$ \\
\hline $\mathrm{CC}$ & 16 & $3.4 \%$ \\
\hline \multicolumn{3}{|l|}{ MTR A2756G } \\
\hline $\mathrm{AA}$ & 393 & $81.9 \%$ \\
\hline AG & 83 & $17.3 \%$ \\
\hline GG & 4 & $0.8 \%$ \\
\hline \multicolumn{3}{|l|}{ MTRR A66G } \\
\hline AA & 155 & $32.7 \%$ \\
\hline $\mathrm{AG}$ & 240 & $50.6 \%$ \\
\hline GG & 79 & $16.7 \%$ \\
\hline
\end{tabular}

BMI: body mass index, SBP: systolic blood pressure, DBP: diastolic blood pressure, Hcy: homocysteine, ALT: alanine aminotransferase, AST: aspartate transaminase, GGT: glutamyl transpeptidase, MTHFR: methylenetetrahydrofolate reductase, MTR: methionine synthase, MTRR: methionine synthase reductase.

were $3.5 \%$ and $4.2 \%$, respectively (16). Serum folate was determined by chemiluminescent immunoassay using a Beckman Coulter ACCESS Immunoassay System (Beckman-Coulter Canada Inc., Mississauga, Canada). The intra- and inter-assay coefficients of variation were $2.3 \%$ and $3.7 \%$, respectively (16). The polymerase chain reaction-restriction fragment length polymorphism (PCR-RFLP) method was applied to detect the MTHFR C677T, MTHFR A1298C, MTR A2756G, and MTRR A66G genotypes. Each genotyping reaction mixture contained 4 ng dried DNA, 0.08 mL 40 assay locus-specific probe, and $2.0 \mathrm{~mL}$ TaqMan universal polymerase chain reaction (PCR) master mix in a final volume of 
Table 2. Associations of gene polymorphisms and measure of hepatic function.

\begin{tabular}{|c|c|c|c|}
\hline Genotypes & ALT & AST & GGT \\
\hline \multicolumn{4}{|l|}{ MTHFR C677T } \\
\hline $\mathrm{CC}$ & $23.0(17.8-32.0)$ & $25.6(21.3-31.0)$ & $20.4(14.0-28.8)$ \\
\hline $\mathrm{CT}$ & $23.1(16.0-33.4)$ & $24.6(20.0-31.0)$ & $21.9(15.0-30.8)$ \\
\hline $\mathrm{TT}$ & $21.7(16.0-32.8)$ & $22.8(18.0-29.3)$ & $20.9(13.0-30.7)$ \\
\hline$r$ & -0.04 & -0.11 & -0.01 \\
\hline$p$ & 0.387 & 0.026 & 0.837 \\
\hline \multicolumn{4}{|l|}{ MTHFR A1298C } \\
\hline $\mathrm{AA}$ & $22.3(16.0-32.5)$ & $24.0(19.0-30.0)$ & $20.6(13.4-29.7)$ \\
\hline $\mathrm{AC}$ & $23.7(17.0-33.0)$ & $25.5(20.9-31.5)$ & $22.4(14.6-31.0)$ \\
\hline $\mathrm{CC}$ & $27.1(22.2-32.0)$ & $26.5(24.5-31.0)$ & $25.1(17.2-29.5)$ \\
\hline$r$ & 0.08 & 0.11 & 0.08 \\
\hline$p$ & 0.081 & 0.032 & 0.088 \\
\hline \multicolumn{4}{|l|}{ MTR A2756G } \\
\hline AA & $22.4(16.0-32.2)$ & $24.1(19.0-30.5)$ & $21.5(14.0-30.9)$ \\
\hline AG & $23.8(17.0-31.8)$ & $25.7(21.0-31.2)$ & $19.5(12.3-24.0)$ \\
\hline GG & $27.4(16.8-41.0)$ & $25.9(22.0-30.0)$ & $31.3(25.0-35.0)$ \\
\hline$r$ & 0.03 & 0.06 & -0.07 \\
\hline$p$ & 0.537 & 0.233 & 0.170 \\
\hline \multicolumn{4}{|l|}{ MTRR A66G } \\
\hline $\mathrm{AA}$ & $23.1(17.0-33.0)$ & $24.6(19.0-31.0)$ & $20.5(13.0-28.2)$ \\
\hline AG & $22.7(16.0-32.0)$ & $24.3(20.0-31.0)$ & $21.4(14.0-29.4)$ \\
\hline GG & $22.5(16.0-36.0)$ & $24.4(20.0-30.0)$ & $22.5(14.0-32.5)$ \\
\hline$r$ & -0.02 & -0.01 & 0.05 \\
\hline$p$ & 0.626 & 0.911 & 0.336 \\
\hline
\end{tabular}

ALT: alanine aminotransferase, AST: aspartate transaminase, GGT: glutamyl transpeptidase, MTHFR: methylenetetrahydrofolate reductase, MTR: methionine synthase, MTRR: methionine synthase reductase.

$4 \mathrm{~mL}$, with the addition of $1.92 \mathrm{~mL}$ sterile water. The main parameters for PCR-RFLP of the four single nucleotide polymorphisms (SNPs) can be seen in our previous report (15). The amplified PCR products were separated on a $3 \%$ agarose gel. To ensure the accuracy of genotyping, genotyping calls were observed by two independent researchers. The genotyping call rate for assessments of all genetic variants was $\geq 98 \%$ in this study.

Statistical analyses were conducted using R v3.2.0 software (http://www.R-project.org/). The results for categorical variables (i.e., sex, clinical centers and genotypes) are presented as number of cases and percentages. Continuous variables (i.e., age, height, weight, body mass index (BMI), systolic blood pressure (SBP), and diastolic blood pressure (DBP)) were given as the mean \pm standard deviation (SD). Since the serum folate, Hcy, ALT, AST and GGT levels were not normally distributed, the geometric means and quartiles $(25 \%$ and $75 \%$ ) were displayed and were logarithmically transformed (the log base is 2) in the subsequent analysis. The Hardy-Weinberg equilibrium for genotypic frequencies of the different genotypes was assessed with the $\chi^{2}$ test. Folate deficiency was defined as a serum folate level $<10 \mathrm{nmol} / \mathrm{L}(15,19)$. Hyperhomocysteinemia (HHcy) was defined as a serum Hcy level $\geq 15 \mu \mathrm{mol} / \mathrm{L}$ $(20,21)$. Spearman rank correlation was used to test the associations of genotypes and serum ALT, AST and GGT level. A unitary linear regression model was used to analyze the correlations of $\log$ (Folate), $\log (\mathrm{Hcy})$ and hepatic functions, as well as the effect of folate deficiency or HHcy on the hepatic functions. Furthermore, a multiple regression model was used to validate the influences of folate deficiency, HHcy and genotypes on $\log$ (ALT), $\log ($ AST $)$ and $\log (\mathrm{GGT})$. A two-sided $p$ value $<0.05$ was considered significant.

\section{RESULTS}

\section{Demographic and clinical characteristics}

A total of 480 patients was recruited for this study. The details of demographic and clinical characteristics are shown in Table 1. In our study, there were 135 $(28.2 \%)$ individuals who had folate deficiency and 143 (29.8\%) individuals with HHcy. Four polymorphisms (MTHFR C677T, MTHFR A1298C, MTR A2756G and MTRR A66G) in this population showed no deviation in genotype distribution from the expected Hardy-Weinberg equilibrium ( $p$ values of $0.855,0.375,0.868$ and 0.391 , respectively).

Associations of gene polymorphisms and hepatic function

The associations of MTHFR C677T, MTHFR A1298C, MTR A2756G and MTRR A66G and hepatic function are shown in Table 2. The mutation of MTHFR C677T showed a negative correlation with serum AST level $(r=-0.11, p=0.026)$. Furthermore, the MTHFR A1298C mutation significantly elevated serum AST level $(r=0.11, p=0.032)$. However, MTR A2756G and MTRR A66G may not affect hepatic function. 

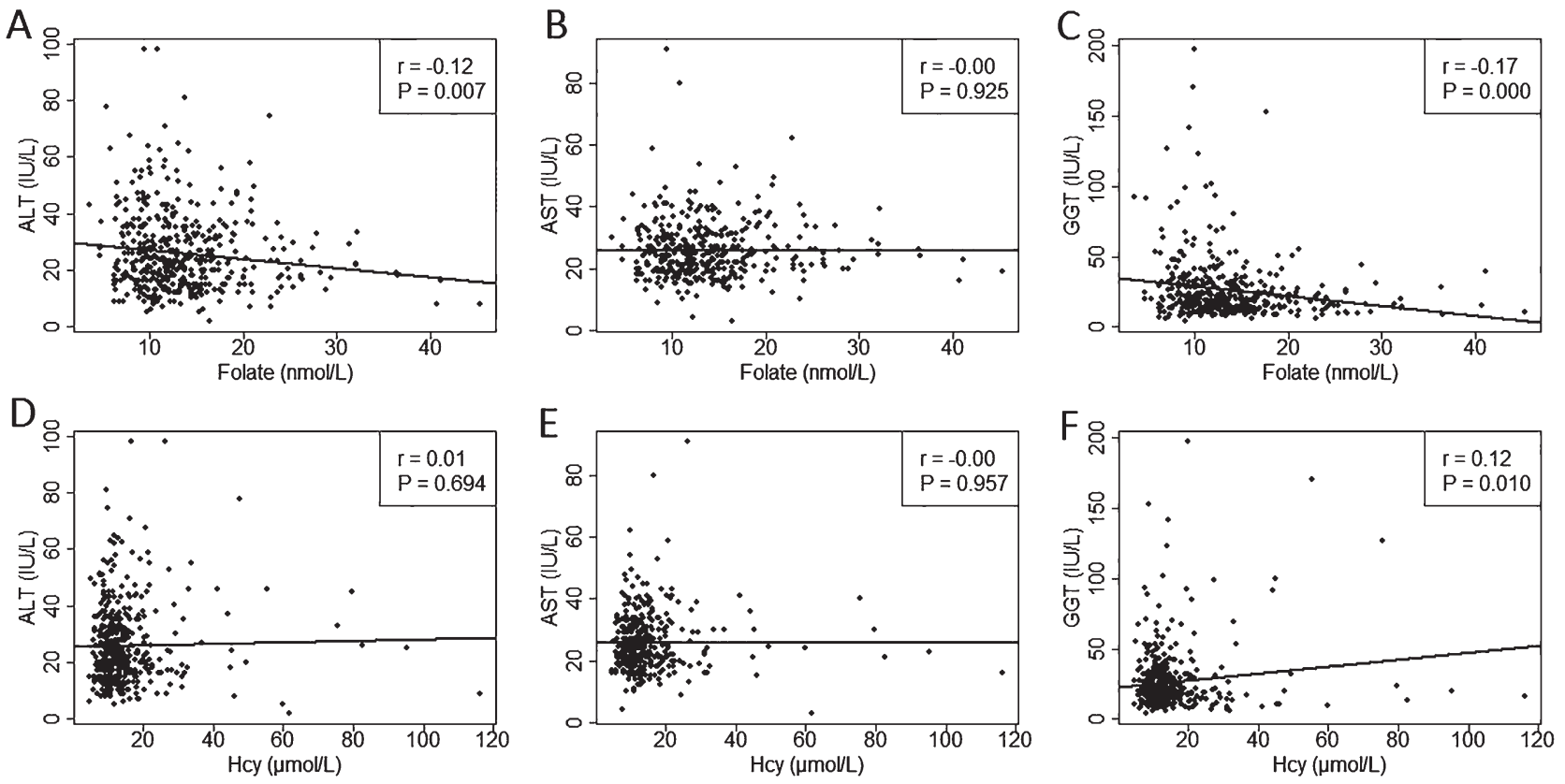

Fig. 1. Correlations between logarithmically transformed data for folate, Hcy and hepatic function. A: folate and ALT; B: folate and AST; C: folate and GGT; D: Hcy and ALT; E: Hcy and AST; F: Hcy and GGT. Hcy: homocysteine, ALT: alanine aminotransferase, AST: aspartate transaminase, GGT: glutamyl transpeptidase.

Table 3. Multiple regression analysis of the influence of folate, Hcy and genotypes on hepatic function.

\begin{tabular}{|c|c|c|c|c|c|c|}
\hline \multirow{2}{*}{ Variables } & \multicolumn{2}{|c|}{$\log (\mathrm{ALT})$} & \multicolumn{2}{|c|}{$\log (\mathrm{AST})$} & \multicolumn{2}{|c|}{$\log (\mathrm{GGT})$} \\
\hline & $\beta(\mathrm{SE})$ & $p$ & $\beta(\mathrm{SE})$ & $p$ & $\beta(\mathrm{SE})$ & $p$ \\
\hline Folate $^{1}$ & $0.13(0.06)$ & 0.031 & $0.02(0.04)$ & 0.586 & $0.18(0.07)$ & 0.011 \\
\hline $\mathrm{Hcy}^{2}$ & $0.00(0.06)$ & 0.982 & $0.06(0.04)$ & 0.133 & $0.00(0.07)$ & 0.947 \\
\hline MTHFR C677T & $0.01(0.04)$ & 0.854 & $-0.04(0.03)$ & 0.143 & $0.04(0.05)$ & 0.374 \\
\hline MTHFR A1298C & $0.08(0.05)$ & 0.138 & $0.04(0.04)$ & 0.333 & $0.12(0.06)$ & 0.052 \\
\hline MTR A2756G & $0.05(0.06)$ & 0.411 & $0.05(0.04)$ & 0.271 & $-0.05(0.07)$ & 0.454 \\
\hline MTRR A66G & $-0.02(0.04)$ & 0.550 & $-0.01(0.03)$ & 0.722 & $0.04(0.04)$ & 0.338 \\
\hline
\end{tabular}

Hcy: homocysteine, ALT: alanine aminotransferase, AST: aspartate transaminase, GGT: glutamyl transpeptidase, MTHFR: methylenetetrahydrofolate reductase, MTR: methionine synthase, MTRR: methionine synthase reductase.

${ }^{1}$ Folate was divided into high folate $(\geq 10 \mathrm{nmol} / \mathrm{L})$ and low folate $(<10 \mathrm{nmol} / \mathrm{L})$.

${ }^{2}$ Hcy was divided into low Hcy $(<15 \mu \mathrm{mol} / \mathrm{L})$ and high Hcy $(\geq 15 \mu \mathrm{mol} / \mathrm{L})$.

Associations of folate, Hcy and hepatic function

The correlation between serum folate and Hcy and hepatic function (ALT, AST and GGT) are shown in Fig. 1. We observed that high folate reduced the serum ALT level $(r=-0.12, p=0.007)$. Furthermore, there was also a negative correlation between folate and GGT $(r=-0.17, p<0.001)$. Additionally, the results showed that a high Hcy level increased the serum GGT level $(r=0.12, p=0.010)$.

Multiple regression analysis on the hepatic functions

We defined folate deficiency, HHcy and genotypes as the independent variables, and used multiple regression models to analyze the effect of these factors on hepatic function (Table 3). The results also showed that folate deficiency increased baseline serum ALT ( $\beta$ (SE): 0.13 (0.06), $p=0.031)$ and GGT level $(\beta$ (SE): 0.18 (0.07), $p=0.011$ ). However, we haven't found any significant association between HHcy, genotypes and hepatic function. Only MTHFR A1298C showed a borderline positive correlation with serum GGT level ( $\beta$ (SE): 0.12 (0.06), $p=0.052$ ).

\section{DISCUSSION}

The present study showed that the MTHFR C677T mutation is associated with decreased serum AST level and the MTHFR A1298C mutation with an increased serum AST level. In contract, the polymorphisms of MTR A2756G and MTRR A66G may not affect hepatic function. Furthermore, the results showed that folate deficiency was a risk factor for hepatic function damage. However, the Hcy level may not affect hepatic function.

NAFLD is defined as a condition in which there is 
excessive fat accumulation in the form of TAG (steatosis) in the liver. Obesity, hypertension and high serum levels of liver enzymes are risk factors associated with NAFLD (22). Our previous study reported that the interactions of Hcy metabolism gene mutations and folate deficiency increased the risk of hypertriglyceridemia and low levels of high-density lipoprotein cholesterol (16). Folate has a role as a methyl group provider involved in the transfer and utilization of one-carbon units, DNA synthesis and methylation process (23). Methyl donor deficiency was associated with disrupting liver function and influencing gene expression profiles that participate in NAFLD, which suggested that folate and vitamin $\mathrm{B}_{12}$ had a beneficial impact on the liver metabolic process (24). Most of the diagnosis of NAFLD is largely based on ALT level (22). Low folate status had already been demonstrated independently to increase the serum ALT level (25). The negative correlation between folate and baseline ALT level was also observed in this study. Furthermore, we have found that a low folate level was associated with an increased GGT level. However, the molecular mechanism of folate and liver damage remains to be studied. HHcy was an independent risk factor for cardiovascular diseases. The damage effect of elevated serum Hcy on NAFLD and other liver damage had also been verified both in epidemiological and clinical studies $(7,14)$, and also in animal experiments (26). The range of Hcy in the present study was 13.2 (9.9-15.9). We found that high Hcy was related to an increased GGT level; however, when multiple linear regression was performed, the significance disappeared.

The MTHFR C677T mutation is located in the catalytic domain of the enzyme and causes an alanine-tovaline substitution at position 222 (27). A previous study demonstrated that this mutation results in a thermolabile enzyme; the homozygous mutation causes an approximately $70 \%$ decrease and the heterozygous mutation results in a 35\% decrease in the mean MTHFR activity (28). The 677TT mutation decreases enzymatic activity and causes a lower rate of reduction of 5,10MTHF to 5-MTHF, resulting in low remethylation rate of Hcy, thus increasing the Hcy level and decreasing the folate level in plasma $(29,30)$. Therefore, this mutation may affect the levels of ALT and AST in the serum (31). However, our results showed the mutation of MTHFR C677T decreased the serum AST level (Table 2). MTHFR A1298C is located in the regulatory domain named NADPH and $S$-adenosylmethionine (SAM) binding site (27). The A1298C mutation does not result in synthesis of a thermolabile protein (30). In the present study, we observed that the mutation of MTHFR A1298C was positively correlated with serum AST level (Table 2).

The MTR A2756G mutation is located at position 919 of the protein and results in substitution of glycine for aspartic acid (32). It is located in a domain of the protein that interacts with SAM and auxiliary proteins that are required for the reductive methylation and reactivation of the cobalamin cofactor, which can be inactivated by oxidation during catalysis $(12,33)$. Therefore, this mutation might impair the binding of SAM and/ or auxiliary proteins and decrease the enzyme activity $(33,34)$. We have recently reported that the MTR 2756 AG + GG mutation was associated with folate deficiency (15). However, in this study we found no association between MTR A2756G and hepatic function.

MTRR A66G results in the replacement of isoleucine by methionine at the peptide position 22 . This mutation is located in the putative flavin mononucleotidebinding domain of the MTRR enzyme, which interacts with MTR (12). Therefore, this mutation may disrupt the binding of MTRR to the MTR-cobalamin-complex, decreasing the rate of Hcy remethylation (32). MTRR A66G had been defined as a risk factor for neural tube defects (NTDs) (35). In this study, we found no correlation between this mutation and these liver enzymes.

In addition to these genetic factors, these liver enzymes levels may also be affected by lifestyle and environmental factors, especially higher alcohol consumption and obesity. A study in Germany showed that smoking, higher alcohol consumption and BMI were significantly positively correlated with serum ALT and AST level, and more weakly correlated with serum GGT level (36). Recently, a meta-analysis including 20,242 samples suggested that obesity and uncoupling protein 2 (UCP2) gene polymorphisms interactively aggravated liver dysfunction (37). Furthermore, in anti-hepatitis $\mathrm{C}$ virus antibody seropositive individuals, Wang et al. found that smoking and higher alcohol consumption independently elevated serum ALT level (38). Moreover, liver damage in obese adolescent girls was enhanced by low folate status and the MTHFR C677T mutation (39).

In conclusion, the polymorphisms of MTHFR C677T and A1298C affect serum AST level. Furthermore, folate deficiency was negatively associated with serum ALT and GGT level. There were some limitations to our study: (1) the study population was small and only contained hypertensive adults, so these results need to be verified in a large population; (2) other B vitamins such as $\mathrm{B}_{6}$ or $\mathrm{B}_{12}$ may also affect hepatic function in ways that we did not determine; (3) we haven't included environmental factors or lifestyle, although these may influence serum ALT, AST and GGT levels. Therefore, we believe that future studies with large samples could be performed to validate our results in a more expansive population.

\section{Acknowledgments}

This work was supported by the National Basic Research Program of China (Grant No. 2013CB835100), the National Natural Science Foundation of China (Grant No. 81570376, No. 31123005 , No. 31401142 and No. 31401137), the Education Revitalization Project of Anhui Province (Grant No. Y05201374), the Natural Science Foundation of Anhui Province of China (Grant No. 1508085MH189), and the Overseas Scientific Collaborative Project of Anhui Province of China (Grant No. 1503062011). We gratefully acknowledge the assistance and cooperation of the faculty and staff of Anhui Medical University and thank all of the participants in our study. 
Wen-Xing Li, Wei Li and Jia-Qian Cao contributed equally to this work.

\section{REFERENCES}

1) Sayiner M, Koenig A, Henry L, Younossi ZM. 2016. Epidemiology of nonalcoholic fatty liver disease and nonalcoholic steatohepatitis in the United States and the rest of the World. Clin Liver Dis 20: 205-214.

2) Stamova B, Jickling GC, Ander BP, Zhan X, Liu D, Turner R, Ho C, Khoury JC, Bushnell C, Pancioli A, Jauch EC, Broderick JP, Sharp FR. 2014. Gene expression in peripheral immune cells following cardioembolic stroke is sexually dimorphic. PloS One 9: e102550.

3) van Beek JH, de Moor MH, de Geus EJ, Lubke GH, Vink JM, Willemsen G, Boomsma DI. 2013. The genetic architecture of liver enzyme levels: GGT, ALT and AST. Behav Genet 43: 329-339.

4) Khattab H, Fouad A, Hamza M, Mohey MA, El-Akel W, Ghoneim H, Abul-Fotouh A, Esmat G. 2015. Relation of ALT and AST levels to the histopathological changes in liver biopsies of patients with chronic hepatitis $\mathrm{C}$ genotype 4. Arab J Gastroenterol 16: 50-53.

5) Barnett MP, Bermingham EN, Young W, Bassett SA, Hesketh JE, Maciel-Dominguez A, McNabb WC, Roy NC. 2015. Low folate and selenium in the mouse maternal diet alters liver gene expression patterns in the offspring after weaning. Nutrients 7: 3370-3386.

6) Qin X, Li J, Cui Y, Liu Z, Zhao Z, Ge J, Guan D, Hu J, Wang Y, Zhang F, Xu X, Wang X, Xu X, Huo Y. 2012. Effect of folic acid intervention on ALT concentration in hypertensives without known hepatic disease: a randomized, double-blind, controlled trial. Eur J Clin Nutr 66: 541-548.

7) Pastore A, Alisi A, di Giovamberardino G, Crudele A, Ceccarelli S, Panera N, Dionisi-Vici C, Nobili V. 2014. Plasma levels of homocysteine and cysteine increased in pediatric NAFLD and strongly correlated with severity of liver damage. Int J Mol Sci 15: 21202-21214.

8) de Carvalho SC, Muniz MT, Siqueira MD, Siqueira ER, Gomes AV, Silva KA, Bezerra LC, D’Almeida V, de Oliveira CP, Pereira LM. 2013. Plasmatic higher levels of homocysteine in non-alcoholic fatty liver disease (NAFLD). Nutr J 12: 37.

9) Barbosa PR, Stabler SP, Machado AL, Braga RC, Hirata RD, Hirata MH, Sampaio-Neto LF, Allen RH, Guerra-Shinohara EM. 2008. Association between decreased vitamin levels and MTHFR, MTR and MTRR gene polymorphisms as determinants for elevated total homocysteine concentrations in pregnant women. Eur J Clin Nutr 62: 1010-1021.

10) Goyette P, Sumner JS, Milos R, Duncan AM, Rosenblatt DS, Matthews RG, Rozen R. 1994. Human methylenetetrahydrofolate reductase: isolation of cDNA, mapping and mutation identification. Nat Genet 7: 195-200.

11) Chen LH, Liu ML, Hwang HY, Chen LS, Korenberg J, Shane B. 1997. Human methionine synthase. cDNA cloning, gene localization, and expression. J Biol Chem 272: 3628-3634.

12) Leclerc D, Wilson A, Dumas R, Gafuik C, Song D, Watkins D, Heng HH, Rommens JM, Scherer SW, Rosenblatt DS, Gravel RA. 1998. Cloning and mapping of a cDNA for methionine synthase reductase, a flavoprotein defective in patients with homocystinuria. Proc Natl Acad Sci USA 95: 3059-3064.

13) Kasapoglu B, Turkay C, Yalcin KS, Kosar A, Bozkurt A.
2015. MTHFR $677 \mathrm{C} / \mathrm{T}$ and $1298 \mathrm{~A} / \mathrm{C}$ mutations and non-alcoholic fatty liver disease. Clin Med 15: 248-251.

14) Franco Brochado MJ, Domenici FA, Candolo Martinelli Ade L, Zucoloto S, de Carvalho da Cunha SF, Vannucchi H. 2013. Methylenetetrahydrofolate reductase gene polymorphism and serum homocysteine levels in nonalcoholic fatty liver disease. Ann Nutr Metab 63: 193-199.

15) Li WX, Dai SX, Zheng JJ, Liu JQ, Huang JF. 2015. Homocysteine metabolism gene polymorphisms (MTHFR C677T, MTHFR A1298C, MTR A2756G and MTRR A66G) jointly elevate the risk of folate deficiency. Nutrients 7: 6670-6687.

16) Li WX, Lv WW, Dai SX, Pan ML, Huang JF. 2015. Joint associations of folate, homocysteine and MTHFR, MTR and MTRR gene polymorphisms with dyslipidemia in a Chinese hypertensive population: a cross-sectional study. Lipids Health Dis 14: 101.

17) Mao G, Hong X, Xing H, Liu P, Liu H, Yu Y, Zhang S, Jiang S, Wang X, Xu X. 2008. Efficacy of folic acid and enalapril combined therapy on reduction of blood pressure and plasma glucose: a multicenter, randomized, double-blind, parallel-controlled, clinical trial. Nutrition 24: 1088-1096.

18) Zhang Y, Qin XH, Li JP, Cui YM, Liu ZY, Zhao ZG, Ge JB, Guan DM, Hu J, Wang YN, Zhang FM, Xu X, Xu XP, Huo Y. 2013. Factors underlying the association of body mass index with serum ALT in Chinese hypertensive adults without known hepatic diseases. J Zhejiang Univ Sci B 14: 743-748.

19) Selhub J, Jacques PF, Dallal G, Choumenkovitch S, Rogers G. 2008. The use of blood concentrations of vitamins and their respective functional indicators to define folate and vitamin B12 status. Food Nutr Bull 29: S67-73.

20) Mahalle N, Kulkarni MV, Garg MK, Naik SS. 2013. Vitamin B12 deficiency and hyperhomocysteinemia as correlates of cardiovascular risk factors in Indian subjects with coronary artery disease. J Cardiol 61: 289-294.

21) Yakub M, Moti N, Parveen S, Chaudhry B, Azam I, Iqbal MP. 2012. Polymorphisms in MTHFR, MS and CBS genes and homocysteine levels in a Pakistani population. PloS One 7: e33222.

22) Veena J, Muragundla A, Sidgiddi S, Subramaniam S. 2014. Non-alcoholic fatty liver disease: need for a balanced nutritional source. Br J Nutr 112: 1858-1872.

23) da Silva RP, Kelly KB, Al Rajabi A, Jacobs RL. 2014. Novel insights on interactions between folate and lipid metabolism. Biofactors 40: 277-283.

24) Chen G, Broséus J, Hergalant S, Donnart A, Chevalier C, Bolaños-Jiménez F, Guéant JL, Houlgatte R. 2015. Identification of master genes involved in liver key functions through transcriptomics and epigenomics of methyl donor deficiency in rat: relevance to nonalcoholic liver disease. Mol Nutr Food Res 59: 293-302.

25) Welzel TM, Katki HA, Sakoda LC, Evans AA, London WT, Chen G, O'Broin S, Shen FM, Lin WY, McGlynn KA. 2007. Blood folate levels and risk of liver damage and hepatocellular carcinoma in a prospective high-risk cohort. Cancer Epidemiol Biomarkers Prev 16: 1279-1282.

26) Suszynska-Zajczyk J, Jakubowski H. 2014. Paraoxonase 1 and dietary hyperhomocysteinemia modulate the expression of mouse proteins involved in liver homeostasis. Acta Biochim Pol 61: 815-823.

27) Shahzad K, Hai A, Ahmed A, Kizilbash N, Alruwaili J. 2013. A structured-based model for the decreased activ- 
ity of Ala222Val and Glu429Ala methylenetetrahydrofolate reductase (MTHFR) mutants. Bioinformation 9: 929-936.

28) Frosst P, Blom HJ, Milos R, Goyette P, Sheppard CA, Matthews RG, Boers GJ, den Heijer M, Kluijtmans LA, van den Heuvel LP, Rozen R. 1995. A candidate genetic risk factor for vascular disease: a common mutation in methylenetetrahydrofolate reductase. Nat Genet 10: 111-113.

29) Zappacosta B, Graziano M, Persichilli S, Di Castelnuovo A, Mastroiacovo P, Iacoviello L. 2014. 5,10-Methylenetetrahydrofolate reductase (MTHFR) C677T and A1298C polymorphisms: genotype frequency and association with homocysteine and folate levels in middlesouthern Italian adults. Cell Biochem Funct 32: 1-4.

30) van der Put NM, Gabreëls F, Stevens EM, Smeitink JA, Trijbels FJ, Eskes TK, van den Heuvel LP, Blom HJ. 1998. A second common mutation in the methylenetetrahydrofolate reductase gene: an additional risk factor for neural-tube defects? Am J Hum Genet 62: 1044-1051.

31) Chatzidakis K, Goulas A, Athanassiadou-Piperopoulou F, Fidani L, Koliouskas D, Mirtsou V. 2006. Methylenetetrahydrofolate reductase $\mathrm{C} 677 \mathrm{~T}$ polymorphism: association with risk for childhood acute lymphoblastic leukemia and response during the initial phase of chemotherapy in greek patients. Pediatr Blood Cancer 47: 147-151.

32) Olteanu H, Munson T, Banerjee R. 2002. Differences in the efficiency of reductive activation of methionine synthase and exogenous electron acceptors between the common polymorphic variants of human methionine synthase reductase. Biochemistry 41: 13378-13385.

33) Harmon DL, Shields DC, Woodside JV, McMaster D, Yarnell JW, Young IS, Peng K, Shane B, Evans AE, White- head AS. 1999. Methionine synthase D919G polymorphism is a significant but modest determinant of circulating homocysteine concentrations. Genet Epidemiol 17: 298-309.

34) Biselli JM, Goloni-Bertollo EM, Haddad R, Eberlin MN, Pavarino-Bertelli EC. 2008. The MTR A2756G polymorphism is associated with an increase of plasma homocysteine concentration in Brazilian individuals with Down syndrome. Braz J Med Biol Res 41: 34-40.

35) Ouyang S, Li Y, Liu Z, Chang H, Wu J. 2013. Association between MTR A2756G and MTRR A66G polymorphisms and maternal risk for neural tube defects: a meta-analysis. Gene 515: 308-312.

36) Breitling LP, Arndt V, Drath C, Brenner H. 2011. Liver enzymes: interaction analysis of smoking with alcohol consumption or BMI, comparing AST and ALT to gamma-GT. PloS One 6: e27951.

37) Vimaleswaran KS, Cavadino A, Verweij N, Nolte IM, Mateo Leach I; LifeLines Cohort Study, Auvinen J, Veijola J, Elliott P, Penninx BW, Snieder H, Järvelin MR, van der Harst P, Cohen RD, Boucher BJ, Hyppönen E. 2015. Interactions between uncoupling protein 2 gene polymorphisms, obesity and alcohol intake on liver function: a large meta-analysed population-based study. Eur J Endocrinol 173: 863-872.

38) Wang CS, Wang ST, Chang TT, Yao WJ, Chou P. 2002. Smoking and alanine aminotransferase levels in hepatitis $\mathrm{C}$ virus infection: implications for prevention of hepatitis C virus progression. Arch Intern Med 162: 811-815.

39) Frelut ML, Emery-Fillon N, Guilland JC, Dao JH, de Courcy GP. 2006. Alanine amino transferase concentrations are linked to folate intakes and methylenetetrahydrofolate reductase polymorphism in obese adolescent girls. J Pediatr Gastr Nutr 43: 234-239. 